\title{
The Structure Optimization of French Intensive Reading Course Based on the Needs Analysis Theory
}

\author{
Haijie Wang \\ School of Foreign Languages \\ China Three Gorges University \\ Yichang, China
}

\begin{abstract}
With the acceleration of economic globalization and the deepening of China's reform and opening up, the exchanges between our country and the French-speaking countries have become more and more extensive, the scale of commercial foreign trade in these countries has been expanding, the Needs for international French-speaking talents is becoming more and more urgent. How to successfully implement the transformation from the single French professional talents training mode which based on language and literature to the "French language and literature + special purpose French" compound French talent training mode, is the key point for the domestic universities to explore the French major. This paper, starting from the analysis of Need of compound French talents and combining the subject characteristics of French intensive reading course, discusses the optimization measures and strategies of intensive reading course for French majors in colleges and universities.
\end{abstract}

Keywords-structure optimization; french intensive reading course; theory of needs analysis

\section{INTRODUCTION}

With China's integration into the international community, the process and pace of international affairs have been accelerated; at the same time, the Needs for internationalized and innovative foreign language talents who have high cultural literacy, international vision and a good knowledge of international rules is becoming more and more urgent. Cultivating high-level talents of French majors requires rational analysis of the students' and society's needs, the formulation of reasonable strategic planning, the exploration and establishment of a scientific personnel training system and model, the equipment of high-quality international teaching staff, and the construction of a curriculum system and teaching material system. It is necessary to provide mechanical and institutional protection by means of the construction of personnel training practice base and international exchanges and cooperation.

This paper, starting from the analysis of Needs of compound French talents and combining the subject characteristics of French intensive reading course, discusses

This paper is the program funded by 2017 Higher Education Research Project of China Three Gorges University ("Study on the structure optimization of French Intensive Reading from the perspective of needs analysis - Take China Three Gorges University for example") and it's also funded by Institute of Wuhan Studies (NO. jhunwyy2015351). the optimization measures and strategies of intensive reading course for French majors in colleges and universities.

\section{THE APPLICATION OF NEEDS ANALYSIS THEORY IN FOREIGN LANGUAGE LEARNING}

Need is a subjective state that occurs when a person lacks a substance, it can be said that it is the desire or eagerness of a person to a certain goal; it is also the driving force for positive activities. In order to understand the needs of the individual, and the society, and to make clear the differences between the actuality and the target, Tom Hutchinson and Alan Waters proposed was proposed the theory of needs analysis which is a process of information gathering and analysis in 1987. They divide the needs into target needs and learning needs. The former (that is the social needs in this study) are objective requirements, which refers to the knowledge and skills that must be learned in order to accomplish the required tasks, especially the communicative situation and the level of the learners in the target situation. Moreover, the target needs can be further divided into the knowledge and skills of must-learn under-learn and want-tolearn. The latter (that is the learner's needs in this study) are subjective needs, which refers to the knowledge and skills that learners must master in their future study or work, including the sequence and the methods of mastery. The analysis of the target needs mainly uses the feedback from the employer to collect the information, so as to understand what the current learners should achieve and the actual deficiency, namely, the gap between the known and the ought-to-know; and the learning needs is mainly the learner's analysis of the expected content or learning method.

At present, there are four models of needs analysis for foreign language learning. The first is John Munby's target scenario analysis model (1978); the second is Dick Allwright's current situational analysis model (1982); the third is the model of Hutchinson \& Waters (1987); the fourth is the model of Dudley-Evans \& St. John (1998), who extensively analyze the language and skills of a particular student group from seven aspects, and synthesize these information to obtain a series of relevant information about the target situation and learning environment. This model reduces the randomness of curriculum design and implementation to a great extent, and its conclusion is more pertinence. This study mainly consults to the last two models, 
and finally obtains the needs analysis framework of this research.

Needs analysis theory was firstly applied to the field of English for Specific or Special Purposes (ESP) and actually it's widely used in foreign language teaching and curriculum design. From the social aspect, Vandermeeren (2005) conducted an investigation into the use and demand of German employees in several Finnish companies, the majority of respondents believed that German culture and adaptability to different cultures were the two most important skills. From this research, it reflects the importance of learners' language application ability; we should pay attention to the cultivation of language application ability and understanding of different cultures in the optimization of curriculum structure. From the learner's point of view, Chaudron (2005) used questionnaires and interviews to analyze the Korean language learning of 84 college students, and establish a task-based teaching module of Korean language (These include the use of target language, the skills needed to complete the task, the characteristics of complex tasks, etc); he finally analyzed the relevant contents of the design and development of the module.

Some experts and scholars in China have introduced the theory of needs analysis. In The Role of Needs Analysis in Foreign Language Teaching, Yu Weihua briefly introduced the connotation and concept of needs analysis, and points out some problems that need to be taken seriously when applying needs analysis to foreign language teaching; in the field of teaching and curriculum based on needs analysis, Wang Haixiao (2004) talked about how to base on the needs analysis to develop a distinctive teaching outline, he thought that teaching needs and teaching conditions had to be carefully analyzed, at the same time, we should weigh the balance of the students, teachers or education workers and society; Dai Jun (2007) also discussed the value and characteristics of needs analysis; According to the requirements of the employer and society for the level of the foreign languages, China's education experts Shu Dingfang has clearly advocated in his works Reform of foreign language teaching: problems and solutions: "In order to meet with the needs of talents of the employers, there should be three or more teaching syllabuses which match to the education teaching courses should be matched to meet the needs of the social talents"...

\section{EXPLORATION AND EXPERIMENT OF STRUCTURE OPTIMIZATION OF FOREIGN LANGUAGE COURSES}

Course structure optimization refers to the proportion of various types of courses in the university curriculum and the form of organization, arrangement and cooperation is more conducive to the development of universities and the realization of the target of talents cultivation (Guo Xiaoming, 2001). It includes the transformation of the composition of the courses and the transformation of the relations among the constituent elements. The course structure should possess three qualities: certain objective basis, high orderliness and strong sequence ability. The course optimization theory includes five principles which should be sequential, continuous, conformable, integrative, and procedural. The studies in the curriculum field indicate that the elements of the courses including course objectives, course content and learning activities.

In addition, in the process of optimizing courses structure, it is necessary to integrate students' development needs, social development needs and disciplinary development needs into the courses under the guidance of certain optimization concepts. In general, there are some characteristics in the courses structure optimization in developed countries' universities, such as broadening the foundation, strengthening general education implementation center, combining problems and practice to set curriculum, integrating the courses-reducing compulsory courses and increasing the proportion of elective courses in the curriculum system, paying attention to the humanities, internationalizing and informationizing the curriculum, etc.

However, in China, people have achieved fruitful results in the reform of university courses, we still need to improve and optimize the course structure in universities and colleges. Up till the present moment, the researchers have put forward the idea of promoting all-round development of human beings in the course of reform of university courses. For example, Professor Zhang Chuting, in The Philosophy of Curriculum and Teaching, believes that the optimization of course structure should be guided by the humanities. In his another work, named The Philosophy of Higher Education, he further revealed the deeper connotation of "humanities leads"-all-round development of human being. Furthermore, the optimization of courses structure in universities should be based on the concept of promoting allround development of human beings and serving people's coordinated development and harmonious development. When curriculum reforms are carried out into the university majors, taking French for example, although it is rare for scholars to discuss the structure optimization of French major courses, many scholars have put forward some opinions and suggestions on different occasions.

Among them, Professor Cao Deming has taken Shanghai International Studies University (SISU) as an example, he noted that SISU was implementing an experimental reform named "student-centered" teaching model, which is based on the National High-quality Course-Elementary French, and which highlights the ability cultivation and thinking training; Huang Guicheng made it clear that the most important thing for French graduates to find a job is to create conditions from the internal environment and to improve the unsound professional structure; $\mathrm{Lu}$ xiaofan believes that it is necessary to adjust the course Settings of French majors, so as to achieve the training goals of "French + special purpose French + English + special purpose English + related majors"; Li Jun, professor of Capital normal university, claimed that we should develop the students' vision, improve their cultural quality, cultivate their basic skills as well as teach French language itself, so that our graduates can well meet the needs of the society and market, and so on. 


\section{THE REQUIREMENTS AND STATUS QUO OF THE FRENCH INTENSIVE READING COURSE SETTING}

In 1988, based on the advantages of various syllabuses such as grammar, structure and function, the instructional documents on elementary teaching in French-The Elementary Stage Syllabus of French Major for Higher Education Institutions clearly pointed out: "The basic skills of languages are the foundation of communicative competence, which is the purpose of language training in elementary stage". For the sake of communicating, people have to possess two abilities: linguistic competence and communicative competence. The former refers to the ability to understand and construct sentences with knowledge of language; the latter refers to the ability to use a wide range of language skills to acquire or express information in a real context.

In 1997, The Senior Stage Syllabus of French Major for Higher Education Institutions further stated: "Our starting point is the end of the elementary stage syllabus. On the one hand, we have higher requirements for listening, speaking, reading, writing and translating, particularly the ability to use language comprehensively. On the other hand, we should focus on expanding the knowledge of language and social culture, and cultivate the ability of working independently, so that students can be qualified for the general translation, teaching and other works in French, and lay a good foundation for further study". According to these purposes, based on the social needs, the local economic development and the theory of second language acquisition, we should change our outdated way of thinking to carry out the reform and practice of the current teaching model of French.

In 2011, another instructional documents of French major-The Standards of Undergraduate French Major for Higher Education Institutions(draft for review) made a clear description of the training objectives for French major: "The education of French major is a part of the humanities and social sciences in higher education institutions, which aims at fostering professional talents in French with high humanistic quality, skilled French language skills, solid knowledge of French language and literature and other related professional knowledge. The talents are also cultivated for the abilities to master French and native language, so that they can be engaged in education, management, translation, foreign affairs, foreign trade, research and other professional works of French.

Nevertheless, the current traditional curriculum system setting of French major still presents inadequacies. French Intensive Reading, a major core course in French, its course structure also exists some unreasonable problems.

First of all, the traditional course system of French Intensive Reading cannot meet the needs of market and society. In the context of economic globalization and market economy, only those who have foreign language skills are faced a sea of troubles in applying for jobs, and those who are welcomed are the compound foreign language talents. At present, the curriculum system of French majors in most Chinese universities and colleges mainly includes the language skills course system, such as listening, speaking, reading, writing, translating and language practice, etc. Even though some universities thought the importance of special purpose French in curriculum setting, they are suffering a lack of "compound" teachers who are both proficient in foreign languages and in professional knowledge, such as business, economics, law, management, and so on. As a result, this has greatly influenced the realization of the target of the compound foreign language talents.

For another, traditional French Intensive Reading courses cannot effectively improve students' intercultural communication skills. For some time, most universities in China have focused on improving the students' language skills in listening, speaking, reading, writing and translating when they taught French Intensive Reading. The students of French major spent a lot of time and energy to learn the basic language skills during the four-year undergraduate study career, but there are still quite a few students who are still unable to understand, speak, write or translate when they graduate. The fundamental reason is that these language skills have not been transformed into communication skills.

In 2001, Committee of Cultural Cooperative Education of European Council have published a book titled Common European Framework of Reference (CEFR), whose primary goal of language teaching is to cultivate intercultural communicative competence and which formulate a detailed standard for European language teaching and assessment. CERF believes that the ability of language communication consisted of three parts: language ability, social language competence and language application ability. The first one includes vocabulary, grammar, semantics, pronunciation, spelling and orthophony; the second one refers to the linguistic ability applied to deal with various social relations and to contact the people of different cultures, it is closely related to social cultures; The last one refers to the ability of language learners to apply language knowledge in the order of organization, structure, arrangement, communicative function and communication.

For instance, if the students can fully cope with the basic language rules of grammar, sentence patterns and vocabularies, they will fully cope with Test for French Majors-Band 4 (TFM-4)/Band 8 (TFM-8); whereas having good intercultural communication means being flexible and able to use language for social interaction, this includes conveying information, expressing feelings and communicating ideas, which is far from being accomplished by rote memorization and repetition. As a consequence, the traditional French Intensive Reading teaching method based on language skills training should be gradually changed to language application. In addition, to improve the students' ability to use language consciously, it is very necessary to increase the practice lessons and to set up group discussion, scenario simulation, debate, etc.

\section{The Proposal to Optimize the Course \\ STRUCTURE OF FRENCH INTENSIVE READING IN THE PERSPECTIVE OF NEEDS ANALYSIS THEORY}

Relative to the Syllabuses and Standards of undergraduate French majors, there are some inadequacies in 
the current course structure of French Intensive Reading. The optimization of its course structure should be carried out in the following several aspects:

\section{A. Make the Teaching System of French Intensive Reading according to the Needs of Society and the Needs of Learners}

According to the needs of the current social employers for the French talents and the needs of the French learners, the teaching system of French Intensive Reading course is constructed with the comprehensive application capacity training.

First, design reasonable teaching objectives. Aim to cultivate students' comprehensive ability in French, the teaching content system of oral expression ability and written communication ability is designed around the application ability. In the teaching process of French intensive reading, we should learn from the "action oriented teaching method" in the Common European Framework of Reference, the focus of language learning should rely on the abilities of language communication and carry out different tasks for different students, finally we take a series of targeted actions by establishing clear goals and specific contents. In class, the teacher selects the text, in which students are interested in the teaching material, then through collaborative imitation training, students are divided into groups and asking students to reproduce the contents of the text according to the specific situation. Thus and thus, the members of each group will learn from each other by paraphrasing, retelling or translating. According to the action oriented approach, the purpose of classroom teaching activities is not limited to the use of French, but also to accomplish a certain task, to achieve certain goals, and the learning of French has the value of social application. While completing the tasks of teachers, students are authentically engaged in real language interaction, thus they realize the application of French independently.

Secondly, formulate normative course standards. As educators or teachers, we should combine the standards of application capacity with the course standards and clear target requirements of knowledge and skills, content and standards, methods and processes, etc. Meanwhile, we should optimize the contents of listening, speaking, reading, writing and translating in French Intensive Reading, and regulate the second class activities in French. The cultivation of students' French application ability is carried out to the teaching standard and course design.

Last but not the least, establish appropriate assessment system. In order to construct an assessment system that reflects the comprehensive application ability of students in French, the requirement for the application of French is embodied. The assessment criteria of listening, speaking, reading, writing and translating should be scientifically formulated, and the teaching effect of French application is actually assessed. At the same time, we should correctly deal with the relationship between the TFM-4/8 and the teaching of the French Intensive Reading, and we should not pursue of the passing rate one-sidedly, but focus on the cultivation and assessment of the language application ability in the course of teaching.

\section{B. Strengthen the Breadth and Depth of Relevant Professional Knowledge}

In a sense, all single specialized disciplines have achieved interdisciplinary integration in different ways. Only by achieving interdisciplinary extension and radiation can the advantage and strength of other disciplines be used to strengthen and develop the discipline effectively. Back in the mid-1980s and early 1990s, some foreign languages institutions, such as Beijing Foreign Studies University, Shanghai International Studies University, Sichuan International Studies University, Guangdong University of Foreign Studies, began to try to cultivate the compound talents. For the time being, this model is not only the need of employment, but also the needs of the Times and the society.

For French majors, for example, when setting up the training objectives, we should fully take the teachers' professional capacities into account, who should not only have solid professional knowledge, fluent French language skills, standard pronunciation and intonation, but also should pay attention to the exemplary appearance and manner, behavior, etc. The relationship of knowledge between "extensive" and "professional" should be adjusted, it is necessary to master both French language skills and professional knowledge, and to have a broad base of knowledge to adapt to the development and change of society.

\section{Enrich the Content of French Intensive Reading Course}

Teaching materials, learning activities and learning experience should be related to each other, which can enrich the content of the course, so that the content will not only reflect the practical problems of the society, but also enable students to acquire the knowledge system and enrich the students' learning experience. In particular, apart from the matched teaching materials, we should supplement some relevant knowledge according to the actual situation of students. In the meantime, the teacher should design various learning activities for students, so that students can study in diverse activities. On this basis, the interaction between learners and the external environment should be increased, and various scenarios suitable for students' abilities and interests should be constructed for students, so that students can gain direct learning experience from the courses.

\section{The Structure Optimization of French Intensive Reading should Be due Consideration to the Construction of Students' Knowledge Structure}

The subject-centered courses theory emphasizes the importance of subject knowledge, which is an important part of the construction of students' knowledge structure. However, the optimization of course structure should not to pay attention to a certain kind of knowledge, but the integration of the learners' knowledge structure. Knowledge, ability and diathesis are the three most important factors for the knowledge structure of French majors. The basic 
composition of knowledge consists mainly of three parts: basic French skills, language knowledge and relevant professional knowledge. Thereinto, Basic skills of French, of course, is refers to the translation, listening, speaking, reading and writing skills; language knowledge includes French language, French culture and the knowledge of Chinese language and culture, etc.; and relevant professional knowledge refers to the professional knowledge related to the works which the high employment of French majors involved in, such as economic, management, architecture, foreign trade, foreign affairs, and so on.

The knowledge structure of French major learners is diverse and unique, and it is necessary to make the most of the knowledge that students already have. Generally speaking, they differ in the original knowledge structure and have different advantages and orientation to the learning of new knowledge. At the same time, students' personal interests and hobbies are different, so we can make use of their respective advantages to achieve their own free development according to their own interests and hobbies. Therefore, it is necessary to consider the integrity of the knowledge structure of French majors as well as the development of students' individuality.

\section{CONCLUSION}

In the wake of the rapid development of politics, economy and culture, the trend of globalization is becoming more and more obvious. In response to the demands of the Age, colleges and universities have set up French majors one after another; foreign language colleges and universities are more likely to be considered as the cradle of French professionals. Due to the importance of foreign language colleges and universities in cultivating the talents of French major, the quality of the training of French professionals ought to be appreciated by the researchers. The cultivation of talents cannot be separated from the rational course structure, so is it reasonable for the course structure of French majors in foreign language institutes? This should not only be analyzed from a one-sided perspective, but also from the three dimensions-society, learners and knowledge.

Course structure is a core element of talents cultivation, and if it lacks reasonable planning, it will not be conducive to the realization of talents training goals. As the core course of French major, the function of French Intensive Reading is undoubtedly to cultivate the students' abilities and diathesis. At the same time, it is necessary to meet the needs of society, and the cultivation of students is based on the rich knowledge and the pursuit of knowledge. Therefore, although the structure optimization of the French Intensive Reading is centered on the needs of learners, it is also necessary to consider the needs of the society for the French major courses. These two needs are not only reasonable, also the relations between them are not antagonistic, but mutually compatible. At the same time, from the perspective of learners' development, the needs of knowledge and learners should bring out the best in each other.

\section{REFERENCES}

[1] Cao Deming, Réflexions sur la formation des talents internationalisés de langue étrangère dans les hautes écoles de langues étrangères [J]. Foreign Language Learning Theory and Practice, 2011 (03):1-5.

[2] Committee of Cultural Cooperative Education of European Council Common European Framework of Reference [M]. Translated by Liu Jun \& Fu Rong. Beijing: Foreign Language Teaching and Research Press, 2008.

[3] D. Nunan, Syllabus Design [M]. Oxford: Oxford University Press, 1991.

[4] E. Hoadley-Maiment, Analyzing Students'Needs [Z]. London: National Center for Industrial Language Training, 1980.

[5] F. Dubin \& E. Olshtain, Course Design [M]. Cambridge: Cambridge University Press, 1985.

[6] Gérard Vigner, Didactique fonctionnelle du français [M]. Paris : Hachette, 1980.

[7] Guo Xiaoming, The concept of holistic curriculum structure and the new thinking of optimizing curriculum structure $[\mathrm{J}]$. Education theory and practice, 2001 (05):38-42.

[8] Hou Heyu, Three concepts of French teaching reform in the higher grades $[\mathrm{J}]$. Teaching Research on French Major in China, 2013,(00):183-194.

[9] Huang Guicheng, Sur la formation des talents polyvalents du français [J]. Shandong Foreign Language Teaching, 1995,(03):54-57.

[10] J.- M Defays et S. Deltour, Le français langue étrangère et seconde, enseignement et apprentissage [M]. Bruxelles : Pierre Mardaga, 2003.

[11] J.D. Brown, The Elements of Language Curriculum: A Systematic Approach to Program Development [M]. Beijing: FLTRP, 2001.

[12] J-C. Beacco, Les dimensions culturelles des enseignements de langues [M]. Paris : Hachette, 2000.

[13] Jiang Guobin, L'utilisation de la bande dessinée dans une méthode de F.L.E [J]. Etudes françaises, 2004 (02):41-50.

[14] Li Jun, Réflexions sur la formation des talents polyvalents du français [J]. Apprendre Le Francais, 2012,(04):61-67.

[15] Lu Xiaofan, A preliminary study on the cultivation model of French compound talents $[\mathrm{J}]$. Chinese French teaching research, 2008,(00):154-160.

[16] M.A. Halliday, A. Mc Intosh \& P. Strevens, The Linguistic Sciences and Language Teaching [M]. London: Longman, 1964.

[17] R. Donato \& R. Tucker, K-12 Language learning and foreign language educational policy: A school-based perspective [J]. The Modern Language Journal, 2007 (91):256-258.

[18] R. Richterich, Identifying the Needs of Adult Learning a Foreign Language [M].Oxford: Pergamon Press, 1980.

[19] Ralph Tyler Bindley, The Role of Needs analysis in Adult ESL Program Design [M]. Cambridge: Cambridge University Press, 1949.

[20] Shu Dingfang, Reform of foreign language teaching: problems and solutions [M]. Beijing: Shanghai Foreign Language Education Press, 2004.

[21] T. Hutchinson \& A. Waters, English for Specific Purposes: A Learning-centered Approach [M]. Cambridge: Cambridge University Press, 1987.

[22] Wang Wenrong(eds.), The Senior Stage Syllabus of French Major for higher education institutions[Z]. Beijing: Foreign language teaching and research press, 1997.

[23] Wei Rining \& Su Jinzhi, Investigation and Analysis of Foreign Language Use in Chinese Big Cities[J]. Foreign Language Teaching and Research, 2011,43(06):924-933+961.

[24] Zhang Chuting, The Philosophy of Higher Education [M]. Beijing: People Education Press, 2003.

[25] Zhang Chuting, The Philosophy of Curriculum and Teaching [M] Changsha: Hunan Education Press, 2004.

[26] Zhuang Zhixiang, Xie Yu, Han Tianlin, Sun Yu, Yan Kai \& Liu Huachu, Reflections on the Cultivation of International and Innovative Foreign Language Talents - Syllabus, Curriculum System, 
Teaching Method and Means [J]. Foreign Language World, 2012,(04):61-67. 